\title{
Sensitivity analysis of the influences of mortar aging and loss on the structural performance of masonry arch aqueducts
}

\author{
Jiang $\mathrm{Hu}^{*}$, and Fuheng Ma \\ State Key Laboratory of Hydrology-Water Resources and Hydraulic Engineering, Nanjing Hydraulic \\ Research Institute, Nanjing 210029, China
}

\begin{abstract}
As commonly used canal system structures, masonry arch aqueducts constitute a significant proportion of Chinese old irrigation infrastructures. Most of these existing aqueducts are well over 50 years old, the deterioration of their constituent materials over time, as well as the development of other defects, significantly affects the mechanical responses of these structures. A deep understanding on the dominant factors that influence the structural safety behaviour of masonry arch aqueducts is essential for determining maintenance and strengthening strategies. Taken the Zhaimen masonry aqueduct in the famous Red Flag Canal as a case study, sensitivity analyses of the influences of mortar aging and loss on the structural performance were carried out. The aqueduct, with unknown geometric dimensions and uncertain physical and mechanical parameters, has defects such as the arch ring detaching from the upper structure and the continuous loss and falling of mortar. The discrete element method (DEM) was employed to analyse the structural behaviour. The results show that the upper structure and the supporting structure are stable under the no bond strength condition. When the mortar is lost locally, the vault position is the most dangerous, followed by the arch shoulder, and then the arch foot part. The mortar loss, manifested as denseness reduction, greatly affects the aqueduct stability. Conversely, the deterioration of the mechanical properties of the mortar, caused by weathering and Calcium ion dissolution due to ambient environment and aqueduct leakage, has relatively little impact on the structural safety. Supplementary grouting of the mortar between the stone masonry should be timely carried out to maintain the structural integrity to ensure the overall stability of the structure. The proposed approach can provide a reference to structural diagnosis and performance assessment for similar structures.
\end{abstract}

\section{Introduction}

Most of the large irrigation districts in China were built in the 1950s and 1960s ${ }^{[1,2]}$. The masonry arch aqueduct uses local materials, and has the advantages of simple structure,

\footnotetext{
* Corresponding author: huj@nhri.cn
} 
easy maintenance, and large bearing potential. Aqueducts play a meaningful role in irrigation projects. In China, many stone masonry aqueducts were constructed to promote the development of irrigation projects in the 1950s and 1960s. Stone masonry aqueducts accounted for a large proportion in many irrigation projects until the 1970s. Thousands of masonry arch aqueducts are still in service as parts of old existing irrigation projects. The canal system structures in service have inevitably suffered damage with time after being subjected to adverse factors, including environmental conditions (wind, rain, freeze-thaw cycles, wet and dry cycles, thermal expansion and contraction), foundation settlement, extreme natural events (earthquakes, floods) and poor maintenance. The combined effect of these adverse environmental factors progressively induces deterioration of physical and mechanical properties of cementitious material of joints. The environmental factors and other factors cause serious deformation and damage, such as ring separation in arch barrels, loss of bricks, distortion of the arch profile, out-of-plane rotation of spandrel walls, and cracks in piers, wing walls and parapets.

Therefore, there is a growing need for a deeper understanding of the structural behaviour of these exiting masonry arch aqueducts to assess their stability and the loadcarrying capacity, in order to assess safety level and inform maintenance, repair and strengthening strategies. Carrying out the structural analysis of the masonry structure is not an easy task. The difficulty is mainly the uncertainty of geometry, materials, damage and actions. This requires research on the methods of detection and assessment of existing masonry arch aqueducts. Several methods, including simple traditional methods and recently developed computerized methods, are available for the assessment of the stability and the load-carrying capacity of masonry arch structures. Among them, the discrete element method (DEM) and the discontinuous deformation analysis method (DDA) provide an advantageous alternative to the continuum-based calculation techniques (e.g., finite element method, FEM) ${ }^{[3-5]}$. The common deterioration of the cementitious material of joints and contacts, as well as the marked nonlinearity of the masonry structure, makes DEM a suitable approach for solving problems involving discontinuities with low bond strength for masonry arch aqueducts.

Considering the uncertainty of geometry and materials of historic masonry structures, sensitivity analysis was carried out to study the influences of mortar aging and loss on the structural performance. The resulting measurement information from the terrestrial laser scanning (TLS) was applied to define a numerical model, which was then used to simulate the behaviour of the aqueduct using DEM. The Zhaimen masonry aqueduct in the famous Red Flag Canal was taken as a case study.

\section{Performance assessment approach}

The main structural components of masonry arch aqueducts are shown in Fig. 1. The arch barrels, the piers and the spandrel walls of most aqueducts were built with either stones bonded by lime slurry or cement mortar. Clearly, the controlling component of the structure is the arch barrel, which is generally built up in one ring of cut stones. Compacted fill is placed on top of the arch barrel to provide a level foundation for the water channel. The compacted fill distributes the upper load over a larger area of the arch extrados and contributes to the load-carrying capacity and the stiffness of the whole masonry arch aqueduct. Two external spandrel walls are built at the edges of the arch barrel and extended into the wing walls beyond the abutments In order to retain the fill over the arch barrel. 


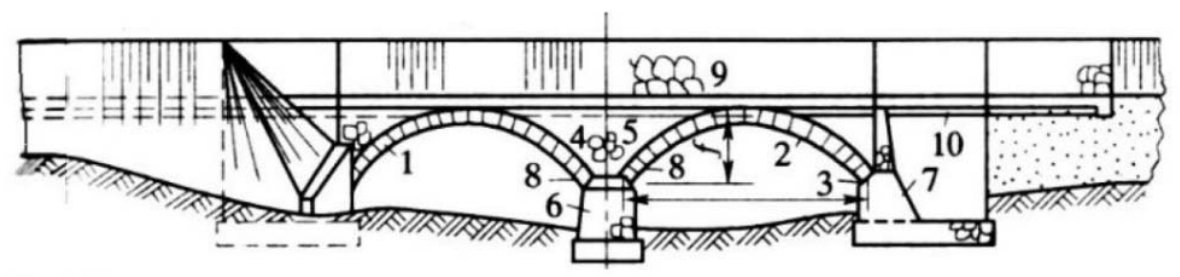

Legend

1. Arch ring; 2. Vault; 3. Arch foot; 4. External spandrel wall; 5. Fill; 6. Pier; 7. Skewback;

8. Drain pipe; 9. Aqueduct body; 10. Cushion

Fig. 1. Main structural components of a masonry arch aqueduct.

A masonry arch aqueduct has its notable characteristics, such as brittle in tension (with almost no tensile strength), friction in shear (once the limited bond among masonry units disappear), inhomogeneity (the presence of stones, mortars, and other cementitious materials), high moisture content due to water penetration, and anisotropy in overall structure (for the response is highly sensitive to the orientation of loads). Masonry arches transmit the upper loads to the ground by the way of compression stresses. Masonry blocks can withstand huge compression; but the mortar (or other cementitious materials) is limited for shear. The tension-resisting capability of an old masonry arch with spoiled mortar is very low.

The force characteristics of the masonry arch aqueduct is characterised by high nonlinearity and discontinuity; and mortar joints act as weakness planes. Considering the uncertainty, the structural performance of a masonry arch aqueduct can be understood only the following factors are known: the characteristics of the masonry texture as a composite material, the structural geometry, and the cross-section (single or multiple leaf walls, connections between the leaves).

As mentioned above, the mortar gradually deteriorates, falls off, and fails for old masonry arch aqueducts after a long service time. There have been serious defects including loss of mortar and serious relative deformation. The distorted masonry shows discrete characteristics. The masonry behaviour is further complicated by the inherent variations in the constituent materials, due to the deterioration caused by weathering processes. Thus addtitional factors, such as what extent the joints are empty or filled with mortar, and the physical, chemical and mechanical characteristics of the components (stones, mortar), should be determined for old exsiting masonry arch aqueducts.

It is important to have an available computational model that can predict the in-service and near-collapse behaviour with sufficient reliability. The DEM model, considering the structure as a collection of separate blocks (i.e., "discrete elements"), can capture the failure mechanisms and quasi-brittle behaviour (i.e. cracking rather than a plastic yield) of a masonry structure. Each of the blocks can be able to move and (in most techniques) to deform independently of each other. The DEM model can be used to model individual blocks, assumed to be elastoplastic or rigid, which are connected by deformable "contact elements". The model is capable of computing large displacements in discontinuous media, and can model the complete detachment of discrete bodies. Thus the DEM model is applied with increasing frequency, simulating the mechanical behaviour of masonry structures more accurately.

Non-linear material, represented by the traditional elastoplastic model, are applied to describle the discrete deformable inner-block (stone block) elements. Stone blocks, bonded together by mortar or other cementitious material, were meshed as rectangles determined by actual dimensions in this study. Interfaces are the locations where mechanical interactions among stone block elements take place and could be potential fracture slip lines. At the interfaces the stone blocks are connected kinematically to each other by sets of point 
contacts, along the outside perimeter of the blocks, at locations where corners or edges meet. It is able to handle various types of geometric interactions among the blocks, inlcuding the edge-to-edge interactions and vertex-to-edge contacts along the joints. It can also take into account large block displacements. For each contact point, there are two spring connections. In this way, both the normal force and the shear force from one block to the other can be transfered. A simple constitutive model, based on a Mohr-Coulomb failure criterion, was assumed for all the contacts in this study.

The mortar joints among stone block elements were represented by the elastic-perfectly plastic coulomb slip-joint area contact. Trial elastic the normal and the shear contact force increments are given by:

$$
\begin{gathered}
\Delta F_{n}=-K_{n} \times \Delta U_{n} \times A_{c} \\
\Delta F_{s}=-K_{s} \times \Delta U_{s} \times A_{c}
\end{gathered}
$$

where $\Delta F_{\mathrm{n}}$ and $\Delta F_{\mathrm{s}}$ are the contact force increments in the normal and shear direction; $K_{n}$ and $K_{s}$ are the joint normal and the joint shear stiffness; $\Delta U_{n}$ and $\Delta U_{s}$ are the normal and the shear contact displacement increments, defined as the relative displacements between the two blocks at the contact point; and $A_{c}$ is the contact area.

Limited tensile $\left(\sigma_{\text {ten }}\right)$ and shear strength $\left(\tau_{\max }\right)$ was assumed in the employed MohrCoulomb model, considering a brittle failure with a drop from peak to residual strength as soon as either normal or shear failure takes place. In the normal direction, the normal stress is set to zero $\left(\sigma_{n}=0\right)$ when the tensile strength exceeds the normal stress $\left(\sigma_{n} \leq \sigma_{\text {ten }}\right)$ and the interface opens. In the shear direction, the explicit incorporation of Coulomb's frictional behaviour was used in the model. Thus, slippage between bricks would occur when the tangential or shear force at a contact exceeds a critical value $\tau_{\max }$ defined by:

$$
\left|\tau_{s}\right|=c+\sigma n \tan \varphi=\tau_{\max }
$$

where $\varphi$ is the friction angle, and $c$ is the cohesive strength.

The equations of motion is solved by the explicit time marching method in this study.

After a contact breaks, forces are redistributed and it might lead to the failure of the adjacent contacts. Cracks are initiated at the contact between interfaces. When the stress applied on the contact exceeds either the tensile or shear strength, inner blocks can separate or slide each other. Thus all cracking at the brick, mortar and/or brick-to-mortar interface can be simulated in this way. The calculations are made using the force-displacement law at contacts and the Newton's second law of motion at blocks nodes. The force-displacement law is used to find contact forces from known displacements, while the Newton's second law governs the motion of the blocks resulting from the known forces acting on the nodes. However the results are sensitive to assumptions about the material properties of the "contact elements", which are essentially unknowable for a real structure.

\section{Project overview and status}

The Red Flag Canal, built on the side of cliffs of the Taihang Mountains, is an irrigation canal located $80 \mathrm{~km}$ northwest of Anyang in the northern extremity of Henan, China. Construction of the canal was started on February 10th 1960, and was completed on April 5th 1965. Even though it was initially only scheduled to be used for 20 years, it is still in use today. After 1990, the aging of the Red Flag Canal was extremely serious. The Red Flag Cana was applied to enlist on the UNESCO World Heritage List. The Zhaimen 
Aqueduct of main trunk channel 1 was investigated as an example in this study ${ }^{[6]}$. The Zhaimen Aqueduct is a 2-hole culvert aqueduct.

As shown in Fig. 2, the structure of arch 1 is relatively normal in appearance, but the spandrel wall and the main arch ring are almost separated, and their gap is obvious. The lime mortar in the main arch ring is severely weathered and spalled, resulting in holes or cracks. There is obvious leakage at the bottom of the arch ring, and water traces and white precipitates are widely distributed. Deformation occurs near the vault, part of the masonry stones moved down seriously. The left and right groove piers are relatively intact, and no obvious defect is observed. The piers are also affected by leakage, thus the lime mortar is severely weathered and powdery. Stones in the arch ring of arch 1 are commonly disjointed. The maximum lime mortar loss depth of the arch ring of arch 1 is $14 \mathrm{~cm}$. The maximum lime mortar loss width and depth of the middle pier are $6 \mathrm{~cm}$ and $17 \mathrm{~cm}$, respectively.
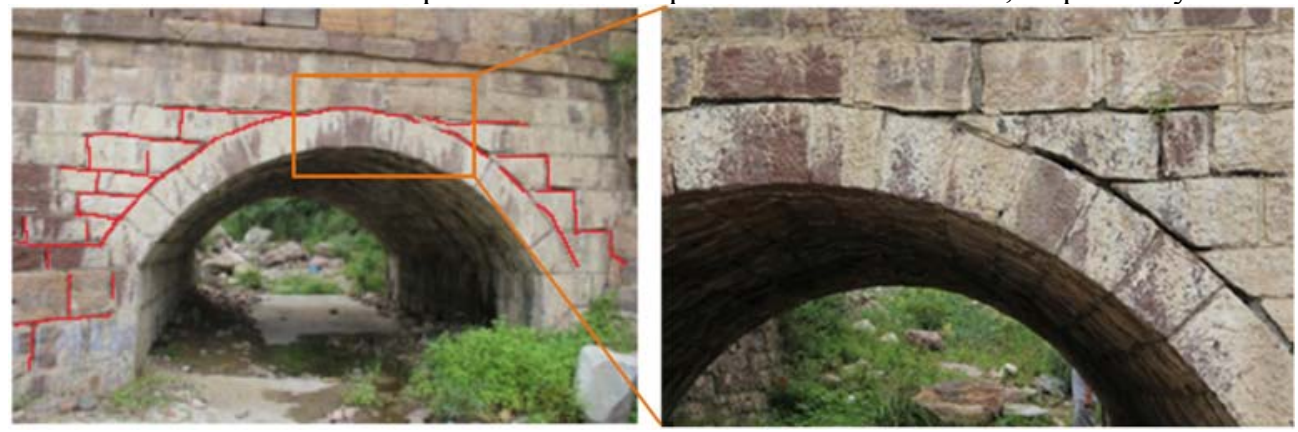

Fig. 2. The arch ring of arch 1 of the aqueduct detached from its upper structure.

As shown in Fig. 3, the lime mortar in the main arch ring of arch 2 is almost lost, the weathering and spalling is severer than arch 1 . The maximum loss depth of the lime mortar 1 reaches $30 \mathrm{~cm}$, and the maximum loss width is $15 \mathrm{~cm}$. The arch is generally humid and drips in many places. The leakage at a typical leakage point is $0.5 \mathrm{ml} / \mathrm{min}$.
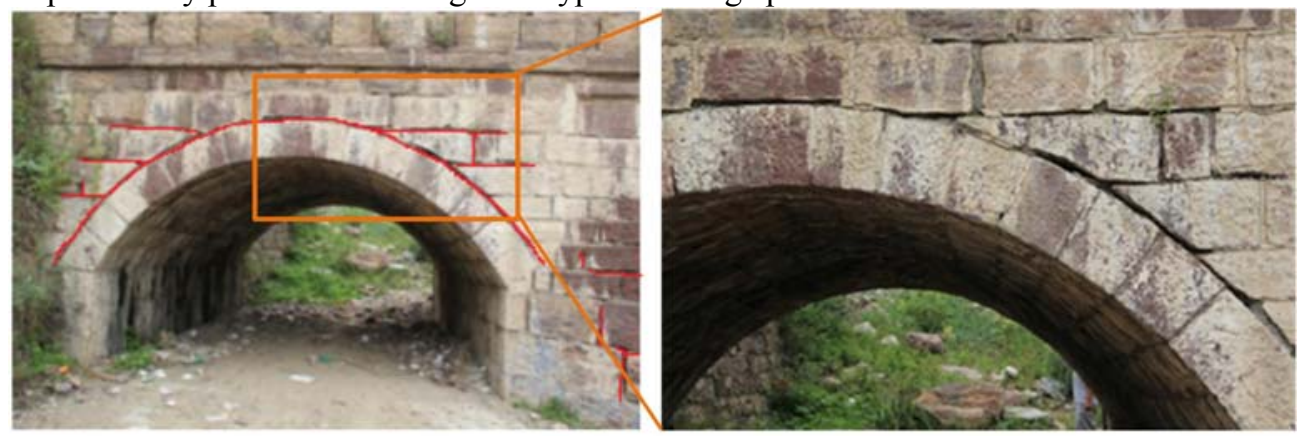

Fig. 3. The arch ring of arch 2 of the aqueduct detached from its upper structure.

The estimated lime mortar strength of the aqueduct body is $2.1 \mathrm{MPa}$, and the standard deviation is $1.3 \mathrm{MPa}$. The engineering geological profile is shown in Fig. 4.

Due to the lack of design drawings, a Leica ScanStation C10 3D laser scanner was used for the 3D surveying of the masonry arch aqueduct. It measures distances in a range of 1$300 \mathrm{~m}$, with a nominal accuracy of $2 \mathrm{~mm}-50 \mathrm{~m}$ in normal illumination and reflectivity conditions. The laser is infrared and has a wavelength of $532 \mathrm{~nm}$. The viewing field has $270^{\circ}$ vertical amplitude and $360^{\circ}$ horizontally. The point acquisition rate is 50000 points per second. The 3D laser scanning measurement adopted an independent coordinate system, and the measurement range includes the outer contour of the aqueduct including the body and the pier, and the structural deformation of the main arch ring. The measurement results 
of the external dimensions are shown in Fig. 5. The geometry of the aqueduct, including its cross sections, elevations, etc, was obtained. The aqueduct has an arch span of $3.97 \mathrm{~m}$, a sagittal span of $1.25 \mathrm{~m}$, a pier height of $0.97 \mathrm{~m}$, and an arch ring thickness of $0.33 \mathrm{~m}$. The aqueduct vector-span ratio is $1 / 3.176$, which is greater than $1 / 5$, is a steep arch.

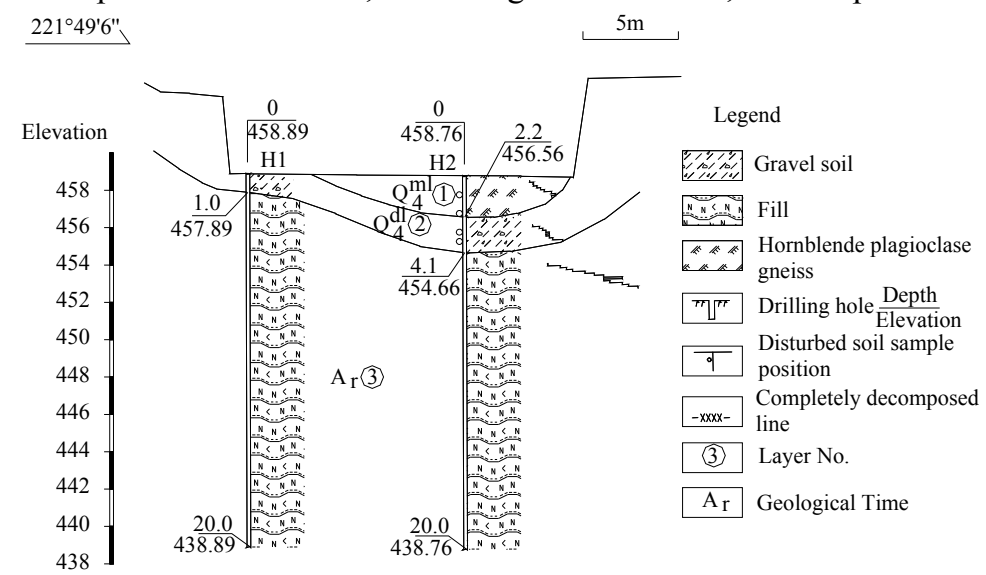

Fig. 4. Engineering geological profile elevations, elevations are given in meters above sea level.

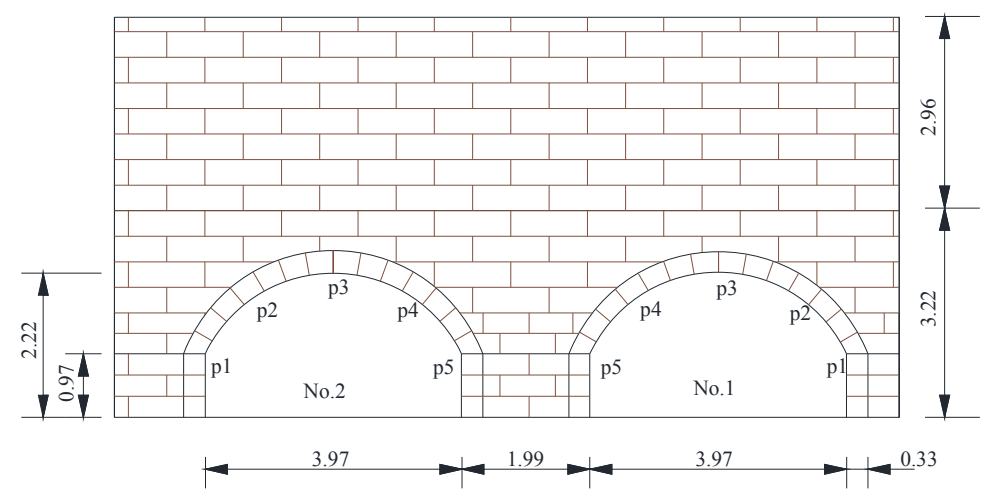

Fig. 5. Cross section dimensions of the masonry aqueduct.

\section{Sensitivity analysis of lime mortar loss and spalling on structural safety}

\subsection{Numerical model}

The DEM model was developed initially to model sliding rock masses in which failure occurs along the joints. This has similarities with the behaviour of low bond strength masonry. The 2D numerical model, as shown in Fig. 6, was constructed according to the actual size and the distribution of masonry stones. From the supplementary geological survey results, from the top to the bottom, the foundation consists of $2.2 \mathrm{~m}$ thick artificial soil layer, $1.5 \mathrm{~m}$ thick gravel soil layer, and $19.0 \mathrm{~m}$ thick gneiss layer. The left and right sides of the model are fixed horizontally and freely in the vertical direction, and the bottom of the model is fixed vertically and freely in the horizontal direction. 


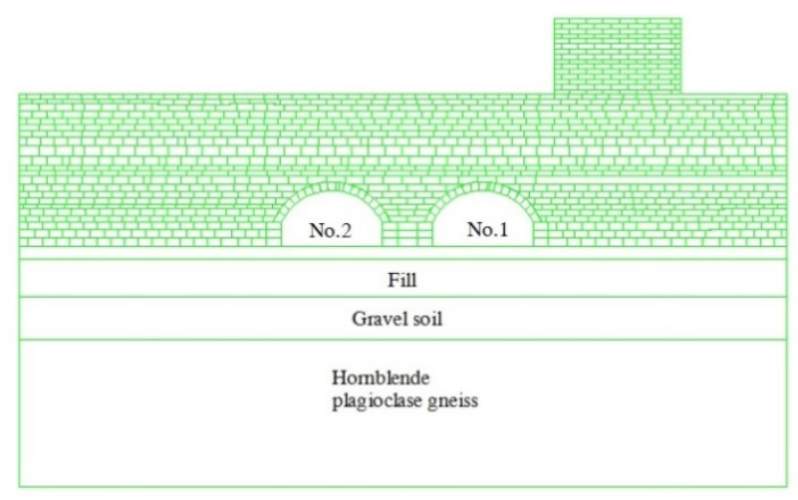

Fig. 6. Numerical model of the masonry aqueduct.

\subsection{Stability analysis}

The supporting structure of the arch aqueduct is composed of three parts: the pier, the main arch ring and the upper structure. The aqueduct body is placed on the arch upper structure. The structure above the arch ring transmits the load to the main arch ring, which generates a strong horizontal thrust on the pier. The main arch ring is the main load-bearing structure with a clear arch axis. The main arch ring transforms the vertical load on the arch into axial pressure and gives the pier a horizontal thrust, thus the bending moment in the arch ring is small.

Structural stability calculations mainly consider the deterioration of lime mortar parameters. Considering the continuous deterioration of the mortar, it was assumed that the strength of the mortar is also 0. Meanwhile, the friction coefficient of masonry stone sliding along cohesive soil is 0.3 . These parameters are used to calculate and analyze the aqueduct stability. The physical and mechanical parameters of masonry and foundation rock are listed in the Table 1, and those of the lime mortar are listed in Table 2.

Table 1. Physical and mechanical parameters of masonry and foundation rock.

\begin{tabular}{|c|c|c|c|c|c|}
\hline Material & $\begin{array}{c}\text { Bulk modulus } \\
(\mathbf{G P a})\end{array}$ & $\begin{array}{c}\text { Shear modulus } \\
(\mathbf{G P a})\end{array}$ & $\begin{array}{c}\text { Cohesion } \\
\mathbf{( k P a )}\end{array}$ & $\begin{array}{c}\text { Density } \\
\left(\mathbf{k g} \cdot \mathbf{m}^{-3} \mathbf{)}\right.\end{array}$ & $\begin{array}{c}\text { Internal friction angle } \\
(\mathbf{})\end{array}$ \\
\hline Masonry & 16.10 & 12.10 & $/$ & 2650.00 & $/$ \\
\hline $\begin{array}{c}\text { Gravel } \\
\text { soil }\end{array}$ & 0.08 & 0.06 & 10.00 & 2280.00 & 20.00 \\
\hline Gneiss & 12.80 & 9.58 & $/$ & 2650.00 & $/$ \\
\hline
\end{tabular}

Table 2. Mechanical parameters of the lime mortar between masonry.

\begin{tabular}{|c|c|c|c|c|}
\hline $\begin{array}{c}\text { Normal stiffness } \\
(\mathbf{G P a} / \mathbf{m})\end{array}$ & $\begin{array}{c}\text { Shear stiffness } \\
(\mathbf{G P a} / \mathbf{m})\end{array}$ & $\begin{array}{c}\text { Internal friction angle } \\
\left({ }^{\circ}\right)\end{array}$ & $\begin{array}{c}\text { Cohesion } \\
(\mathbf{k P a})\end{array}$ & $\begin{array}{c}\text { Tensile strength } \\
(\mathbf{k P a})\end{array}$ \\
\hline 8.20 & 6.60 & 16.70 & 0.00 & 0.00 \\
\hline
\end{tabular}

The results show that the aqueduct is dominated by the main compressive stress, which is consistent with the characteristics of the arch structure. There are small tensile stresses between the masonry stones, the maximum value is $0.1 \mathrm{MPa}$. For the arch ring, the maximum principal compressive stress value at positions 1 and 5 is $1.6 \mathrm{MPa}$, followed by positions 2, 4, and 3 respectively. The maximum principal stress of the arch ring is less than the strength of the lime mortar $(2.1 \mathrm{MPa})$, and the strength of arches 1 and 2 can still meet the operating requirements. Stress concentration appears at position 5 , which conforms to the stress distribution law of the arch ring. However, the stress does not exceed the lime 
mortar strength, and the stress concentration area is small, which does not affect the structural safety. Therefore, the strength of the masonry and the lime mortar of the arch ring meet the requirements, and the arch ring is still stable in the current status.

\subsection{Sensitivity analysis of lime mortar loss and spalling on structural safety}

Another issue of the lime mortar deterioration is the powdering, weathering and loss. Sensitivity analysis, addressing the gap between the main arch ring and the upper structure, and the stability of the arch ring, was carried out considering the loss of the lime mortars. The considered positions of the lime mortar loss were also the aforementioned positions 1-5. Meanwhile, different loss widths such as $4 \mathrm{~cm}, 8 \mathrm{~cm}$, and $12 \mathrm{~cm}$ were considered. In addition, the condition the lime mortar is evenly shed is also considered, and the result is compared with the concentrated shedding. The maximum displacement and the maximum gap under different lime mortar shedding widths of arches 1 and 2 are respectively shown in Fig. 7. The results of the above cases are discussed separately below.

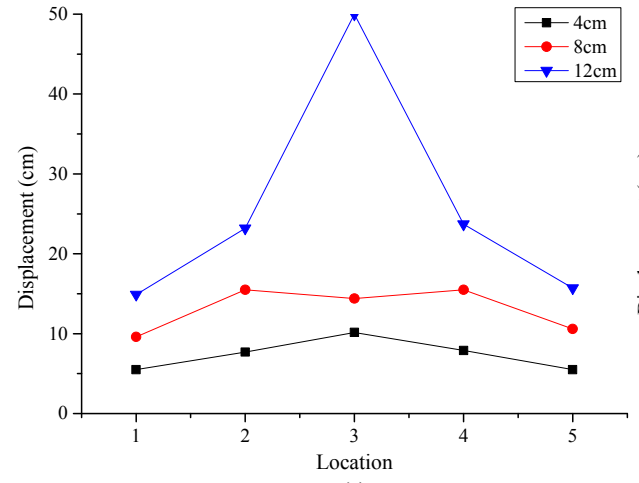

(a)

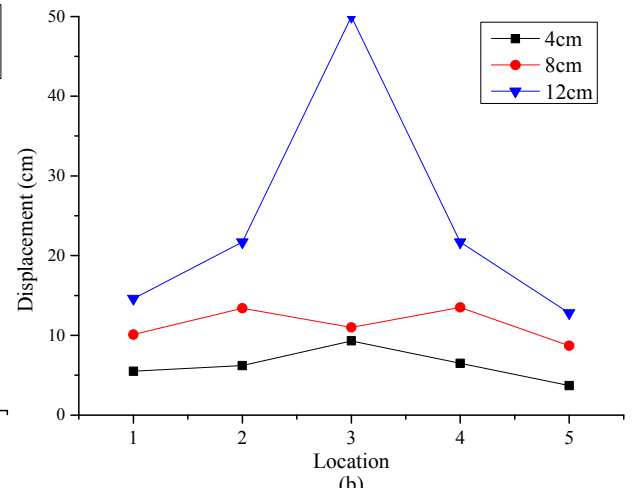

(b)

Fig. 7. Maximum displacement and gap under different lime mortar shedding widths: (a) arch 1, and (b) $\operatorname{arch} 2$.

For position 3, the maximum displacement of the arch ring masonry, as well as the gap, increases rapidly with the increase of the lime mortar shedding width. When the shedding widths are $4 \mathrm{~cm}$ and $8 \mathrm{~cm}$, the maximum displacements are $10.15 \mathrm{~cm}$ and $14.4 \mathrm{~cm}$, respectively. When the shedding width reaches $12 \mathrm{~cm}$, the arch ring completely collapses. The displacement fields of the aqueduct, for position 3 with different widths, are shown in Fig. 8. When the shedding width is $12 \mathrm{~cm}$, the arch ring completely collapses, and the calculation does not converge. The intercepted illustration is the intermediate calculation result.

For position 1, the displacement of the arch ring masonry also increases as the shedding width increases. The maximum displacement of the arch ring masonry is linearly related to the shedding width. When the shedding width is $12 \mathrm{~cm}$, the maximum displacement is 14.9 $\mathrm{cm}$. The masonry movement direction is biased towards the mortar falling position, and the maximum displacement is near the vault. The increase law of the gap width is similar to that of the displacement.

For position 2, the maximum displacement of the arch ring masonry increases rapidly as the mortar shedding width increases. When the shedding width is $12 \mathrm{~cm}$, the maximum displacement is $23.2 \mathrm{~cm}$. The masonry movement direction is also biased towards the mortar falling position, and the maximum displacement is near the vault. The increase law of the gap width is similar to that of the displacement too.

The results of the mortar shedding at positions 4 and 5 are similar to those at positions 2 and 1 , respectively. 

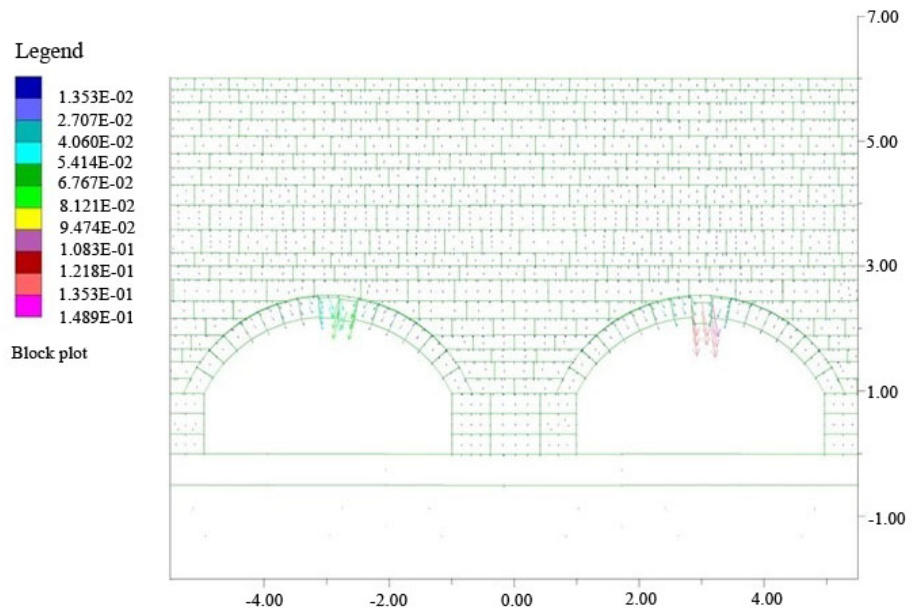

(a)
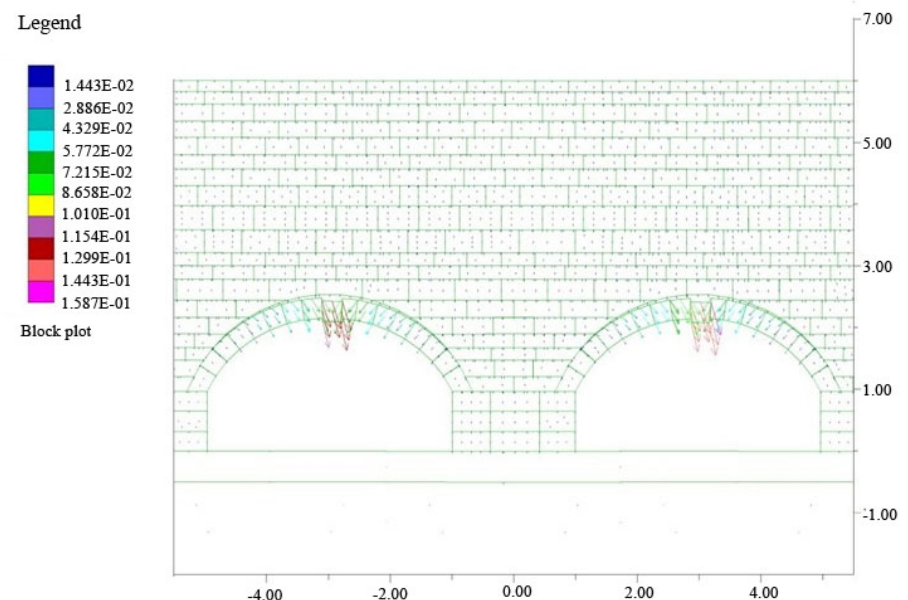

(b)
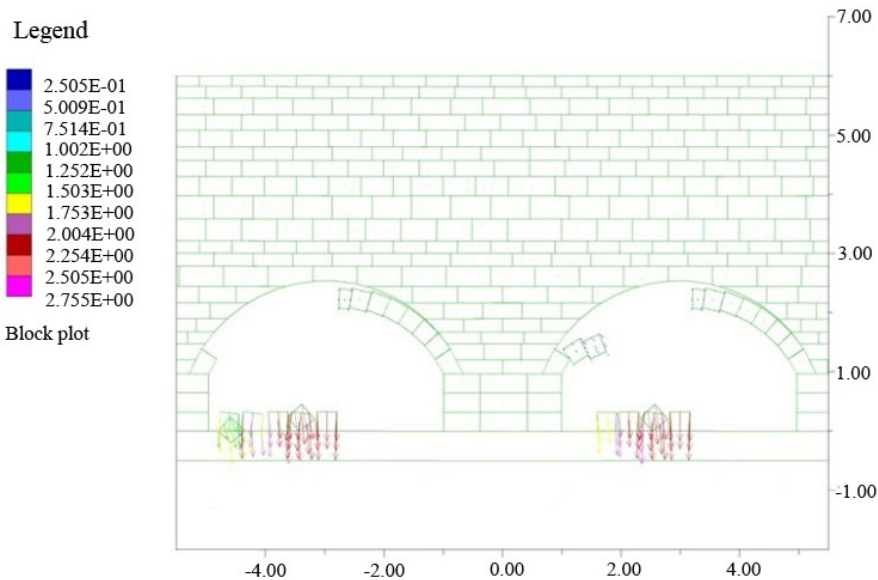

(c)

Fig. 8. Displacement fields of the masonry aqueduct under different lime mortar shedding conditions (Unit: $\mathrm{m}$ ): (a): $4 \mathrm{~cm}$, (b) $8 \mathrm{~cm}$, and (c) $12 \mathrm{~cm}$. 
When the mortar sheds evenly at these positions, the masonry displacement of the arch ring and the gap increase as the mortar shedding width increases (Fig. 9). The maximum displacement of the arch ring masonry is linearly related to the shedding width. When the shedding width is $12 \mathrm{~cm}$, the maximum displacement is $13.5 \mathrm{~cm}$. The maximum displacement is near the vault.

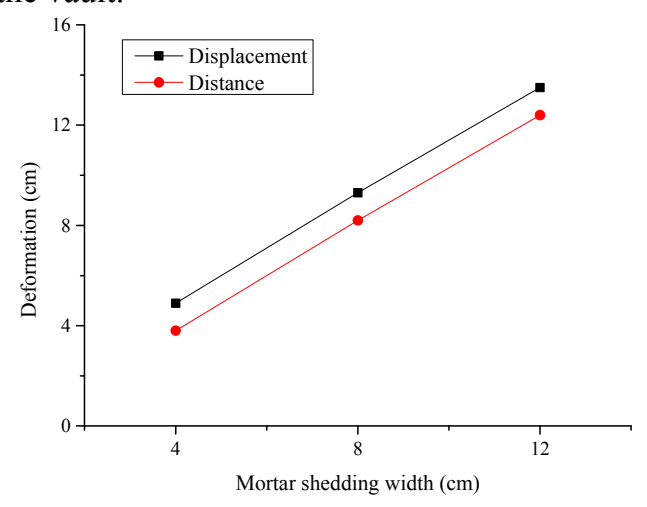

Fig. 9. The maximum displacements and the gap between the main arch ring and the upper structure results due to lime mortar shedding.

\subsection{Result discussions}

In the case of deterioration of lime mortar mechanical parameters, according to conservative calculations, the aqueduct structure including the aqueduct arch ring, the upper structure and the supporting structure are stable, and the bearing capacity of the foundation meets the stability requirements.

The aqueduct stability is affected by the location and the degree of lime mortar loss. When the lime mortar is intensively lost, the vault position is the most dangerous, followed by the arch shoulder, and then the arch foot part. If the lime mortar is evenly lost, the risk of dispersed loss is less than that of concentrated loss. In other words, the loss of lime mortar greatly affects the stability of the aqueduct. The drop of lime mortar density caused by shedding loss has a great impact on the stability of the aqueduct. Conversely, deterioration of mortar parameters is not the dominant factor.

Chemical grouting material with large elastic modulus and durability should be used to fill the joints, in order to improve the compactness between the masonry. Anti-seepage measures should be taken to the bottom of the aqueduct to stop the leakage, and to slow down the lime mortar degradation of the masonry caused by long-term leakage and water chemistry action. The focused location is the arch vault, followed by the arch shoulder, and then the arch foot.

\section{Conclusions}

In this paper, sensitivity analysis of mortar loss and spalling on structural safety for a masonry arch aqueduct under different mortar loss locations and widths in the arch ring was carried out.

The aqueduct stability is not significantly affected by the degradation of mechanical properties of mortar, but obviously affected by mortar loss. The mortar loss at the vault is most dangerous, followed by the arch shoulder, and then the arch foot part. The influence of dispersed loss is less than those of concentrated loss. 
For the stone masonry aqueduct, maintenance of the mortar between the stone masonry should be timely carried out to maintain the structural integrity to ensure the overall stability of the structure. Measures should also be taken to prevent the leakage of the aqueduct, so as to avoid the long-term erosion and shedding of the mortar.

\section{Acknowledgements}

This research was supported by the National Natural Science Foundation of China (grant no. 51879169; 51779155), and the Fundamental Research Funds for the Central Public Welfare Research Institute (No. Y720002; Y720003). The authors wish to acknowledge the support of the Red Flag Canal Management Office. The authors thank Haijun Wang and Peiying Gu for their technical support.

\section{References}

1. J. Wang, Y. Zhu, T. Sun, J. Huang, L. Zhang, B. Guan, Q. Q. Huang, Aust. J. of Agr. and Resour. Ec. 64(1) (2020)

2. X. Zhu, Y. Li, M. Li, Y. Pan, P. Shi, J. Soil Water Conserv. 68(6) (2013)

3. P. Roca, M. Cervera, G. Gariup, L. Pela, Arch. Comput. Method E. 17(3) (2010)

4. F. Portioli, L. Cascini, Eng. Struct. 148 (2017)

5. B. Pulatsu, E. M. Bretas, P. B. Lourenco, Earthq. Struct. 11(4) (2016)

6. J. Hu, F. Ma, Safety Assessment of Red Flag Canal, Nanjing Hydraulic Research Institute, Nanjing, China. (2019) 